\title{
Synthesis of Novel Bis(terpyridyl)benzene Derivatives as Organic Modules in Organic-Metallic Hybrid Polymers
}

\author{
Masayoshi Higuchi*,a, Yuhki Otsuka and Dirk G. Kurth ${ }^{\text {ab }}$

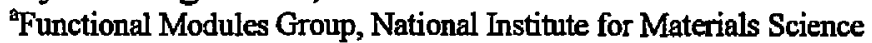 \\ 1-1 Namiki, Tsukuba 305-0044, Japan \\ ${ }^{b}$ Max Planck Institute of Colloids and Interfaces, \\ Research Campus Golm, 14467 Potsdam, Germany \\ Fax: 81-29-860-4721, e-mail: HGUCHI.Masayoshi@nims.go.jp
}

\begin{abstract}
As novel organic modules in organic-metallic hybrid polymers, bromo-substituted bis(terpyridyl)benzenes were prepared via condensation of aromatic dienones with pyridinium salts in the presence of ammonium acetate. The organic-metallic hybrid polymer was obtained by complexation of dibromo-substituted bis(terpyridyl)benzene with iron(II) acetate. We investigated electrochemical and spectroscopic properties using cyclic voltammetry and UV-vis spectral measurement and revealed a substituent effect of the bromo groups.

Key words: Organic-metallic hybrid polymers, Bis-terpyridines, Complexation, Electrochemical properties, Polymerization
\end{abstract}

\section{INTRODUCTION}

Organic-metallic hybrid polymers have received much attention as novel functional materials, because they are expected to have unique electrochemical, photochemical, or magnetic properties based on electronic interaction between organic modules and metal ions. ${ }^{1}$ In addition, their properties can be enhanced and controlled by choosing suitable organic modules and metal ions. Therefore it is important to exploit novel organic modules using various synthetic methods. Especially $\pi$-conjugated compounds with many coordination sites are good candidates as the organic modules, ${ }^{2}$ because electrochemical interaction between metal ions through a $\pi$-conjugated backbone of the organic modules is expected to cause high conductivity or multi-electrons transfer. However, it is not so easy to synthesize novel organic modules, because their synthetic methods are limited. We herein report synthesis of bromo-substituted bis-terpyridines as novel organic modules with a $\pi$-conjugated structure, formation of the hybrid materials by complexation of them with metal ions, and the electrochemical effect by introduction of the electron-withdrawing groups.

\section{EXPERIMENTAL SECTION}

\subsection{General methods}

All reagents were reagent grade and were used without purification. De-ionized $\mathrm{H}_{2} \mathrm{O}$ was used in the experiment where required. ${ }^{1} \mathrm{H}$ NMR spectra were recorded at $300 \mathrm{MHz}$ on a JEOL AL $300 / \mathrm{BZ}$ instrument. Chemical shifts were given relative to TMS. Mass spectra (MS) were measured by using AXIMA-CFR, Shimadzu/Kratos TOF Mass spectrometer. High resolution mass spectra (HRMS) were measured by using Shimadzu
LCMS-IT-TOF spectrometer. Cyclic voltammograms were measured on an electrochemical analyzer, ALS/H CH instruments, with a platinum wire counter electrode and $\mathrm{Ag} / \mathrm{Ag}^{+}$ reference electrode in an anhydrous and argon saturated $0.1 \mathrm{~mol} \mathrm{~L}^{-1}$ acetonitrile solution of tetra-n-butylammonium perchlorate $\left(n-\mathrm{Bu}_{4} \mathrm{NClO}_{4}\right)$. UV-vis spectra were measured by using Shimadzu UV spectroscopy (UV-2550). Analytical thin layer chromatography (TLC) was Merck aluminium oxide $60 \mathrm{~F}_{254}$ neutral or silica gel $60 \mathrm{~F}_{254}$ coated on 25 TCC aluminium sheets $(20 \times 20 \mathrm{~cm})$. Flash column chromatographic separations were performed on silica gel $60 \mathrm{~N}$ (neutral, 40-100 $\mu \mathrm{M}$ ), Kanto Chemical Co. Inc., or activated alumina oxide (75 $\mu \mathrm{M})$, Wako.

\subsection{Synthesis of bromo-substituted terpyridines 4} and 5

2-Actyl-6-bromopyridine $(5.0 \mathrm{~g}, 25 \mathrm{mmol})$ and iodine $(6.4 \mathrm{~g}, 25 \mathrm{mmol})$ were refluxed in pyridine (12 $\mathrm{ml}$ ) for $30 \mathrm{~min}$. The resulting wax was washed in diethylether and water and dried in vacuum. Pyridinium salt 1 was obtained in an $85 \%$ yield ( 8.6 g).

4-Bromobenzaldehyde $(5.0 \mathrm{~g}, 27 \mathrm{mmol})$ was totally dissolved in a mixture of potassium hydroxide $(1.5 \mathrm{~g}, 27 \mathrm{mmol})$, water $(10 \mathrm{ml})$, and methanol $(75 \mathrm{ml})$. 2-Acetylpyridine was added to the solution and the reaction mixture was stirred for 2 days at room temperature. After filtration, the crude product was washed in methanol and dried in vacuum. Enone 2 was isolated in a $60 \%$ yield (4.7 g).

Pyridinium salt 1 (4.92 g, $12.1 \mathrm{mmol}$ ), enone 2 $(3.50 \mathrm{~g}, 12.1 \mathrm{mmol})$, and ammonium acetate $(23.4$ $\mathrm{g}, 304 \mathrm{mmol}$ ) were added to dehydrated methanol $(200 \mathrm{ml})$ and the mixture was refluxed for $12 \mathrm{~h}$. 
After filtration, the residue was washed in water and methanol and re-precipitated in chloroform/hexane. After drying in vacuum, dibromo-terpyridine 4 was obtained in a $40 \%$ yield $(2.27 \mathrm{~g})$. Spectral data of $4:{ }^{1} \mathrm{H}$ NMR $\left(\mathrm{CDCl}_{3}\right) \delta=$ 8.75-8.69 $(2 \mathrm{H}, \mathrm{m}), 8.66-8.60(3 \mathrm{H}, \mathrm{m}), 7.92-7.84$ $(1 \mathrm{H}, \mathrm{m}), 7.79-7.70(3 \mathrm{H}, \mathrm{m}), 7.68-7.62(2 \mathrm{H}, \mathrm{m})$, 7.56-7.51 (1H, m), 7.40-7.33 (1H, m); HRMS: Calcd for $\mathrm{C}_{21} \mathrm{H}_{14} \mathrm{Br}_{2} \mathrm{~N}_{3}$ : $\left(\mathrm{M}+\mathrm{H}^{+}\right)$465.9549, Found: $\mathrm{m} / \mathrm{z}$ 465.9559. Tribromo-terpyridine 5 was also obtained with the same synthetic procedure. Spectral data of $5:{ }^{1} \mathrm{H}$ NMR $\left(\mathrm{CDCl}_{3}\right) \delta=8.64(2 \mathrm{H}$, s), 8.60-8.55 $(2 \mathrm{H}, \mathrm{m}), 7.77-7.63(6 \mathrm{H}, \mathrm{m}), 7.56-7.52$ $(2 \mathrm{H}, \mathrm{m})$; HRMS: Colcd for $\mathrm{C}_{21} \mathrm{H}_{13} \mathrm{Br}_{3} \mathrm{~N}_{3}:\left(\mathrm{M}+\mathrm{H}^{+}\right)$ 543.8654, Found: $\mathrm{m} / \mathrm{z} 543.8690$.

\subsection{Synthesis of bromo-substituted bis-terpyridine 8 and 9}

Terephtalcarboxyaldehyde $(3.6 \mathrm{~g}, 27 \mathrm{mmol})$ was totally dissolved in a mixture of potassium hydroxide $(3.0 \mathrm{~g}, 54 \mathrm{mmol})$, water $(20 \mathrm{ml})$, and methanol (150 ml). 2-Acetylpyridine $(6.0 \mathrm{ml}, 54$ mmol) was added to the solution and stirred for 2 days at room temperature. After filtration, the residue was washed in methanol and dried in vacuum. Dienone 6 was obtained in an $88 \%$ yield (8.1 g).

Pyridinium salt 1 (7.89 g, $19.5 \mathrm{mmol})$ and dienone $6(3.32 \mathrm{~g}, 9.74 \mathrm{mmol})$ were added in a mixture of ammonium acetate $(37.5 \mathrm{~g}, 487 \mathrm{mmol})$ and dehydrated methanol $(250 \mathrm{~mL})$ and the mixture was refluxed for $12 \mathrm{~h}$. After filtration, the residue was washed in water, methanol, and acetic acid and extracted in toluene. The solution was concentrated and the product was re-crystallized in acetic acid. Dibromo-bis-terpyridine 8 was obtained in a $20 \%$ yield $(1.36 \mathrm{~g})$. Spectral data of 8: ${ }^{1} \mathrm{H}$ NMR $\left(\mathrm{CDCl}_{3}\right) \delta=8.83-8.79(2 \mathrm{H}, \mathrm{m})$, 8.78-8.74 (4H, m), 8.68-8.62 (4H, m), 8.05 $(4 \mathrm{H}, \mathrm{s})$, 7.94-7.86 (2H, m), 7.78-7.71 (2H, m), 7.57-7.52 $(2 \mathrm{H}, \mathrm{m}), 7.41-7.35(2 \mathrm{H}, \mathrm{m})$; HRMS: Calcd for $\mathrm{C}_{36} \mathrm{H}_{23} \mathrm{Br}_{2} \mathrm{~N}_{6}$ : $\left(\mathrm{M}+\mathrm{H}^{+}\right)$679.0345, Found: $\mathrm{m} / \mathrm{z}$ 679.0333. Tetrabromo-substituted bis-terpyridine 9 was obtained with the same synthetic procedure. Spectral data of $9:{ }^{1} \mathrm{H} \mathrm{NMR}\left(\mathrm{CDCl}_{3}\right) \delta=8.77(4 \mathrm{H}$, s), 8.63-8.59(4H, m), 8.06 (4H, s), 7.77-7.70 (4H, m), 7.58-7.53 (4H, m); HRMS: Calcd for $\mathrm{C}_{36} \mathrm{H}_{21} \mathrm{Br}_{4} \mathrm{~N}_{6}: \quad\left(\mathrm{M}+\mathrm{H}^{+}\right)$852.8519, Found: $\mathrm{m} / \mathrm{z}$ 852.8556 .

\section{RESULTS AND DISCUSSION}

\subsection{Synthesis of novel bis-terpyridines}

Bis-terpyridines are one of the interesting organic modules and complexed with various metal ions such as iron or cobalt ions. ${ }^{3}$ Organic-metallic hybrid materials including bis-terpyridines show unique electrochemical or magnetic properties unlike conventional organic polymers." For example, a hybrid polymer with a linear structure is formed by complexation of bis(terpyridyl)benzene with iron(II) acetate (Scheme 1). Properties of the polymers can be controlled by introduction of electron-withdrawing or -releasing groups to bis-terpyridines, since the properties are caused by electronic interaction between bis-terpyridines and metal ions. However, it is not so easy to modify bis-terpyridines because of a limitation of synthetic methods. We succeeded to synthesize novel bis(terpyridyl)benzenes with bromo groups as an electro-withdrawing group (Schemes 2 and 3). The bromo-substituted compounds will be also useful as a starting material in the further modification by nickel(0)-catalyzed condensation and cross-couplings using palladium( 0 )-complexes such as Suzuki, Stille, Sonogashira reactions.

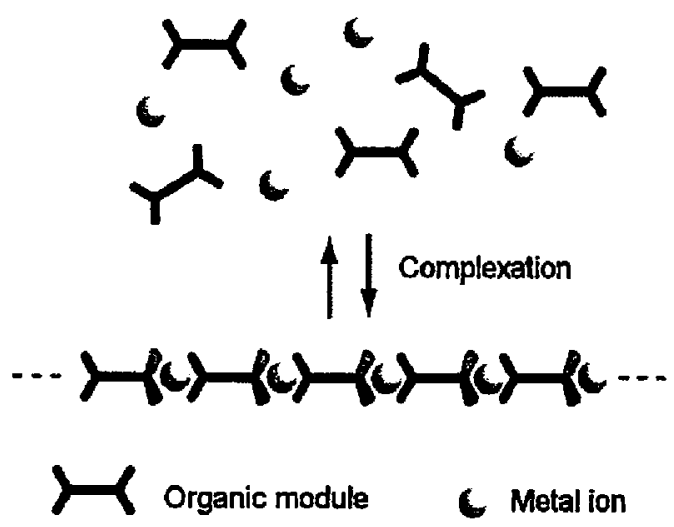

Scheme 1. Formation of organic-metallic hybrid polymers with a linear structure by complexation of organic modules with metal ions.

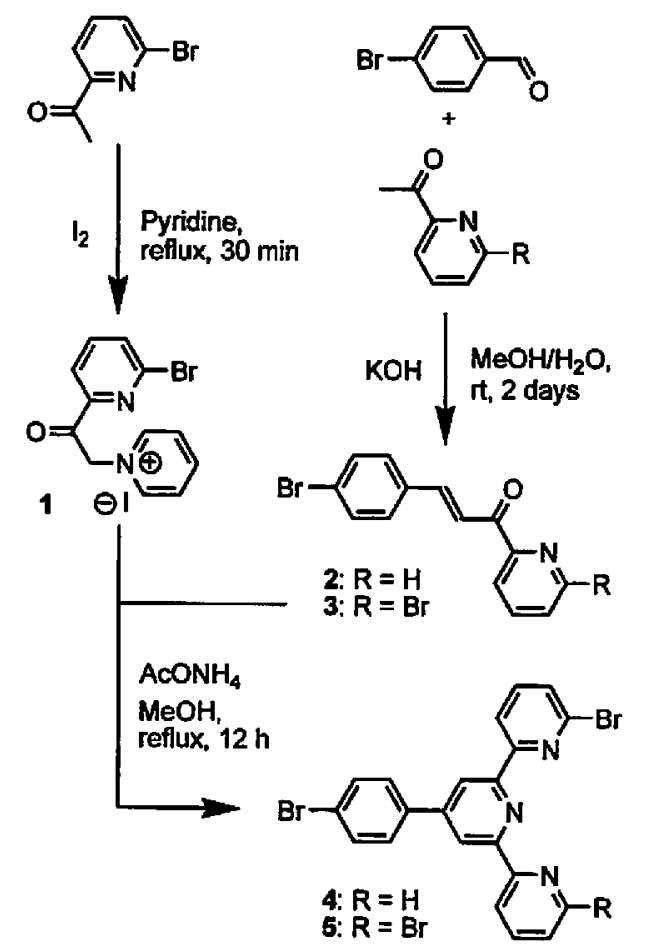

Scheme 2. Synthesis of bromo-substituted terpyridines. 
Among commonly used approaches to synthesize terpyridines, we chose the Krơhnke-type method ${ }^{6}$ starting from a aldehyde and a 2-acetylpyridine, because various substituents can be introduced to terpyridines by using 2-acetylpyridine derivatives as a starting material. A synthetic scheme of a model compound of bromo-substituted bis-terpyridines is shown in Scheme 2 . Dibromo-terpyridine 4 and tribromo-terpyridine 5 are identified by NMR and HRMS. Modification of a spacer unit in bis-terpyridines has been reported, but introduction of functional groups to 2-position of the pyridine moieties has not been reported as far as we know. With the similar method used in the model compounds, bromo-substituted 1,4-bis(terpyridyl)benzenes are synthesized (Scheme 2). Bromo-substituted 1,4-bis(terpyridyl)benzenes 8 and 9 are obtained during condensation of dienones 6 and 7 with pyridinium salt 1 in the presence of ammonium acetate, respectively, and identified by NMR and HRMS.

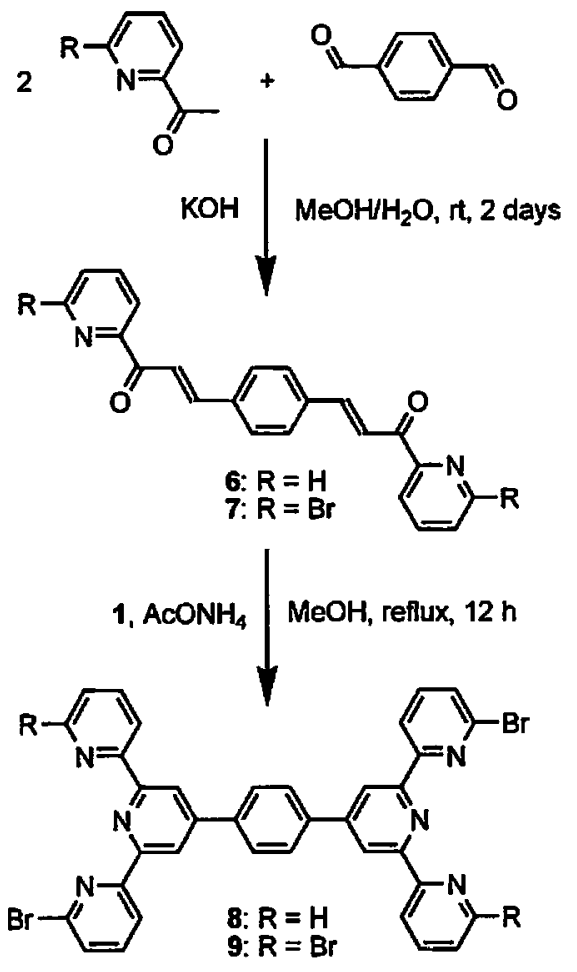

Scheme 3. Synthesis of bromo-substituted bis-terpyridines.

3.2 Synthesis of an organic-metallic hybrid polymer including bromo-substituted bis-terpyridine

A organic-metallic hybrid polymer having bromo-substituted bis(terpyridyl)benzene 8 is obtained by complexation of 8 with iron(II) acetate. The Synthetic procedures are as follows: Same molar weights of the organic module and iron acetate are added in acetic acid, and refluxed for 24 h. After the reaction, a hybrid polymer including the organic module 8 is obtained quantitatively by evaporation of the solvent. During the reaction, a color of the solution becomes green based on the metal-to-ligand charge transfer (MLCT) absorption caused by the complexation. On the other hand, no color change is observed during complexation of tetrabromo-substituted bis-terpyridine 9 with iron(II) acetate, which shows that no polymer is formed under the reaction conditions. It is probably because steric hindrance and/or electrostatic repulsion between bromo groups of the organic modules prevent an iron ion to be complexed with two organic modules.

\subsection{Electrochemical properties}

Electrochemical properties of the polymer are investigated by cyclic voltammetry. The measurement is carried out using a three-electrode cell in an anhydrous $\mathrm{CH}_{3} \mathrm{CN}$ solution of tetr- $n$-butyl ammonium perchlorate $(0.1 \mathrm{M})$. The solution is purged with argon for $15 \mathrm{~min}$ prior to scan. A redox potential of iron ions in the polymer is $0.57 \mathrm{~V}$ vs. $\mathrm{Ag} / \mathrm{Ag}^{+}$(Figure 1), which is more negative than that of a hybrid polymer consisting of bis(terpyridyl)benzene with iron(II) ions ( 0.77 V). The negative shift is probably caused by the electron-withdrawing effect of the bromo groups. This result means that introduction of substituents at the 2-position of pyridine is effective to control a redox potential of the hybrid polymers. The electron-withdrawing effect of the organic module is supported by UV-vis spectroscopy. A hybrid polymer consisting of bis(terpyridyl)benzene with iron(II) ions has the MLCT absorption around 580 nm in the UV-vis spectrum. On the other hand, the MLCT absorption of the polymer bearing bromo groups appears at $600 \mathrm{~nm}$ in the UV-vis spectrum. The shift to longer wavelength means that bromo-substituted bis-terpyridine has higher LUMO energy than bis-terpyridine due to the electron-withdrawing effect of the bromo groups.

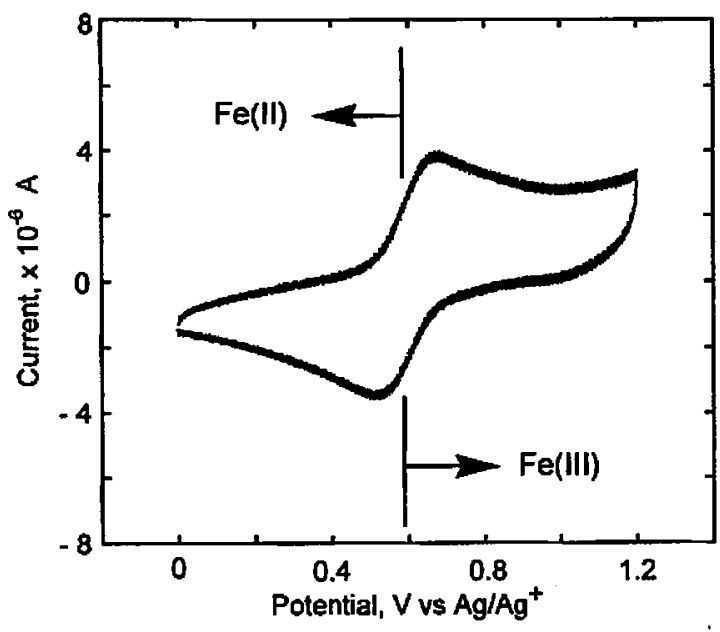

Fig. 1. Cyclic voltammogram of a hybrid polymer formed by complexation of dibrormo-substituted bis-terpyridine 8 with iron(II) acetate in $0.1 \mathrm{M}$ 
$n$ - $\mathrm{Bu}_{4} \mathrm{NClO}_{4} /$ acetonitrile at room temperature. (scan rate: $100 \mathrm{mV} / \mathrm{sec}$; electrode: carbon disk).

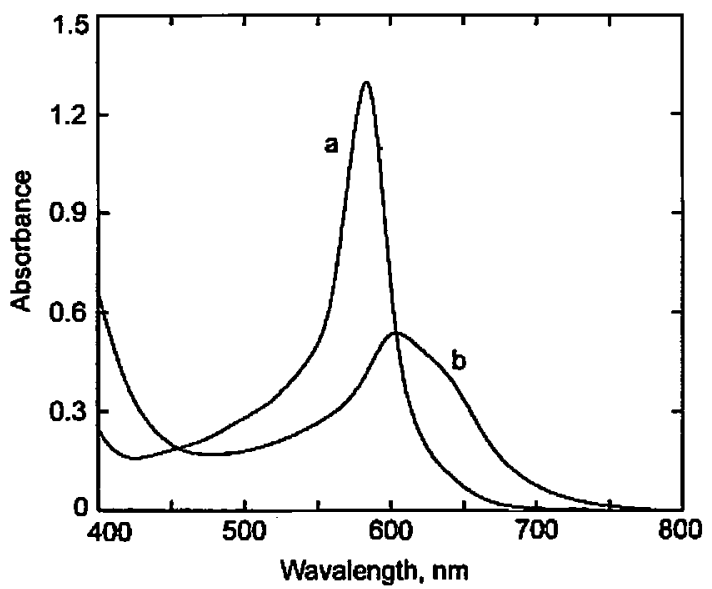

Fig. 2. The MLCT absorption in UV-vis spectra of hybrid polymers formed by complexation of iron(II) acetate with (a) bis(terpyridyl)benzene and (b) dibrormo-substituted one 8 ([polymer unit] $=5.0 \times 10^{-6} \mathrm{M}$ ).

\section{CONCLUSIONS}

We synthesized novel terpyridines bearing bromo groups as an electron-withdrawing substituent by condensation of enones with a pyridinium salt in the presence of ammonium acetate. Novel organic-metallic hybrid polymer was formed by complexation of dibromo-substituted bis(terpyridyl)benzene with iron(II) acetate in an acetic acid. During the complexation, a color of the solution became green based on the MLCT absorption. Electrochemical measurements of the polymer showed a negative shift of the redox potential of the iron ions due to the strong electron-withdrawing effect of the bromo groups. The similar effect was observed as a red shift of the MLCT absorption in the UV-vis spectrum of the polymer. We revealed that introduction of a substituent to a 2-position of the pyridine units dramatically changes electrochemical properties of the hybrid polymers obtained by complexation.

\section{References}

[1] (a) T. Yasuda, I. Yamaguchi, and T. Yamamoto, Adv. Mater., 15, 293-296 (2003). (b) K. Yamamoto, M. Higuchi, S. Shiki, M. Tsuruta, and H. Chiba, Nature, 415, 509-511 (2002). (c) U. Kolb, K. Bủscher, C. A. Helm, A. Lindner, A. F. Thünemann, M. Menzel, M. Higuchi, and D. G. Kurth, Proc. Natl. Acad. Sci. USA, 103, 10202-10206 (2006). (d) N. Severin, J. P. Rabe, and D. G. Kurth, J. Am. Chem. Soc., 126, 3696-3697 (2004).

[2] (a) T. Yamamoto, Macromol. Rapid Commun., 23, 583-606 (2002). (b) T. Yamamoto and $H$. Kokubo, Electrochimica Acta, 50, 1453-1460 (2005).

[3] (a) H. Hofmeier and U. S. Schubert, Chem. Soc.
Rev., 33, 373-399 (2004). (b) P. R. Andres and U. H. Schubert, Adv. Mater., 16, 1043-1068 (2004). [4] (a) C. N. Carlson, C. J. Kuehl, R. E. Da-Re, J. M. Veauthier, E. J. Schelter, A. E. Milligan, B. L. Scott, E. D. Bauer, J. D. Thompson, D. E. Morris, and K. D. John, J. Am. Chem. Soc., 128, 7230-7241 (2006). (b) P. P. Lainé, F. Bedioui, F. Loiseau, C. Chiorboli, and S. Campagna, J. Am. Chem. Soc., 128, 7510-7521 (2006). (c) K. Sénéchal-David, J. P. Leonard, S. E. Plush, and T. Gunnlaugsson, Org. Lett., 8, 2727-2730 (2006). (d) E. Coronado, J. R. Galán-Mascarós, C. Marti-Gastaldo, E. Palomares, J. R. Durrant, R. Vilar, M. Grätzel, and M. K. Nazeeruddin, J. Am. Chem. Soc., 127, 12351-12356 (2005). (e) E. C. Constable and J. Lewis, Polyhedron, 1, 303-306 (1982). (f) Y. Uchida, M. Okabe, H. Kobayashi, and S. Oae, Synthesis-stuttgart, 939-940 (1995).

[5] (a) A. Suzuki, J. Organometal. Chem., 576, 147-168 (1999). (b) J. P. Wolfe, R. A. Singer, B. H. Yang, and S. L. Buchwald, J. Am. Chem. Soc., 121 9550-9561 (1999). (c) S. Kotha, K. Lahiri, and D. Kashinath, Tetrahedron, 58, 9633-9695 (2002). (d) T. Hundertmark, A. F. Littke, S. L. Buchwald, and G. C. Fu, Org. Lett., 2, 1729-1731 (2000). (e) S. Thorand and N. Krause, J, Org. Chem., 63, $8551-8553$ (1998). (f) V. Farina and B. Krishnan, $J$. Am. Chem. Soc., 113, $9585-9595$ (1991). (g) V. Farina, S. Kapadia, B. Krishnan, C. Wang, and L. S. Liebeskind, J. Org. Chem., 59, 5905-5911 (1994). [6] (a) S. Vaduvescu and P. G. Potvin, Eur. J. Inorg. Chem., 1763-1769 (2004). (b) F. Kröhnke, Synthesis, 1-24 (1976).

(Received December 28, 2006;Accepted March 8, 2007) 